\title{
Niobate Nanosheets as Catalysts for Photochemical Water Splitting into Hydrogen and Hydrogen Peroxide
}

\author{
Owen C. Compton and Frank E. Osterloh* \\ Department of Chemistry, University of California-Davis, One Shields Avenue, Davis, California 95616
}

Received: September 3, 2008; Revised Manuscript Received: October 26, 2008

\begin{abstract}
Tetrabutylammonium-stabilized $\mathrm{Ca}_{2} \mathrm{Nb}_{3} \mathrm{O}_{10}$ nanosheets catalyze photochemical splitting of water into hydrogen and hydrogen peroxide under UV irradiation. The peroxide forms on the surface of the catalyst and adsorbs to it, fully deactivating the catalyst after $48 \mathrm{~h}$ of irradiation. For the Pt-modified niobate, complete deactivation occurs within $24 \mathrm{~h}$ due to higher $\mathrm{H}_{2}$ evolution rate with this system. The peroxide was identified via Raman and IR spectroscopy. In vibrational spectra, the irradiated niobate exhibits bands at 580, 778, and $940 \mathrm{~cm}^{-1}$, which suggest that the peroxide is present as a side-on ligand coordinated to the $\mathrm{Nb}^{5+}$ ions on the nanosheet surface. The same species can be formed by treating the nanosheets with $30 \%$ aqueous $\mathrm{H}_{2} \mathrm{O}_{2}$. If the catalyst is irradiated in $\mathrm{H}_{2}{ }^{18} \mathrm{O}$, the bands shift to lower energy, indicating that the peroxide species is formed from water. Room-temperature storage of the nanosheets in $\mathrm{H}_{2}{ }^{18} \mathrm{O}$ also leads to isotopic exchange of all $\mathrm{Nb}-\mathrm{O}$ atoms over the course of $24 \mathrm{~h}$. Peroxide amounts measured by titration of the catalyst with $o$-tolidine after 6 , 12 , and $24 \mathrm{~h}$ of irradiation form in a 1:1 stoichiometry with hydrogen. Infrared data shows that the peroxide is partially desorbed by evacuating the catalyst and by purging with argon gas. Under catalytic conditions, this treatment restores up to $60 \%$ of the original activity. For the $\mathrm{H}_{2} \mathrm{O}_{2}$-treated catalyst, near quantitative $\mathrm{H}_{2} \mathrm{O}_{2}$ desorption occurs within $20 \mathrm{~min}$ at $450{ }^{\circ} \mathrm{C}$. Separate irradiation experiments of the catalyst in the presence of air reveal that $\mathrm{H}_{2}$ evolution is diminished and that $\mathrm{O}_{2}$ uptake occurs from the atmosphere. Most of the hydrogen peroxide formed under these conditions is subsequently detected in the supernatant and only small amounts on the catalyst. NMR spectra show that the tetrabutylammonium cations are decomposed. These findings suggest that there are two distinct pathways for peroxide formation, one involving one-electron reduction of $\mathrm{O}_{2}$ and one involving two-electron reduction of water (in the absence of $\mathrm{O}_{2}$ ).
\end{abstract}

\section{Introduction}

Since the discovery of photooxidation of water with $\mathrm{TiO}_{2}$ (rutile) by Fujishima and Honda in 1971, ${ }^{1,2}$ the photocatalytic water splitting reaction (eq 1) has been widely investigated as a possible process for generating fuel. ${ }^{3-5}$ Catalysts for this reaction typically consist of a compound semiconductor and a fused metal or metal oxide cocatalyst. If the band gap of the material is large enough (at least $2.4 \mathrm{eV}),{ }^{6,7}$ irradiation of an aqueous catalyst dispersion can lead to $\mathrm{H}_{2}$ and $\mathrm{O}_{2}$. However, for many metal oxides, including the anatase form of $\mathrm{TiO}_{2},{ }^{8-11}$ several titanates, and niobates $\left(\mathrm{KCa}_{2} \mathrm{Nb}_{3} \mathrm{O}_{10},{ }^{12} \mathrm{Sr}_{2} \mathrm{Nb}_{6} \mathrm{O}_{7},{ }^{13}\right.$ and $\mathrm{K}_{4} \mathrm{Nb}_{6} \mathrm{O}_{17}{ }^{14}$ ), $\mathrm{O}_{2}$ evolution is often substoichiometric or no $\mathrm{O}_{2}$ is observed at all, even though the band gaps of these semiconductors are suitable for overall splitting of water. Grätzel and later Arakawa's group ${ }^{15-17}$ have investigated this phenomenon in greater detail. For anatase powders with or without Rhor Pt-cocatalysts, it was found that no $\mathrm{O}_{2}$ is evolved and that $\mathrm{H}_{2}$ evolution ceases after 28 h. ${ }^{9-11,18-20}$ Using a redox active dye it was shown that peroxide/superoxide species were produced during the reaction (eq 2), and that these species adsorbed to the catalyst surface and deactivated it over time. However, the binding geometry of the peroxides could not be determined. Also it was not clear if the peroxide formed by two-electron oxidation of water as shown in eq 6 , or by fourelectron oxidation of water (eq 1 ), followed by two-electron reduction of $\mathrm{O}_{2}$ (eq 3 ).

* To whom correspondence should be addressed.

$$
\begin{aligned}
& \mathrm{H}_{2} \mathrm{O} \stackrel{h v, \text { cat }}{\longrightarrow} \mathrm{H}_{2}+1 / 2 \mathrm{O}_{2} \\
& 2 \mathrm{H}_{2} \mathrm{O} \stackrel{h v \text {, cat }}{\longrightarrow} \mathrm{H}_{2}+\mathrm{H}_{2} \mathrm{O}_{2 \text { (ads) }} \\
& 2 \mathrm{H}^{+}+2 \mathrm{e}_{\mathrm{CB}}^{-}+\mathrm{O}_{2} \stackrel{h v, \text { cat }}{\longrightarrow} \mathrm{H}_{2} \mathrm{O}_{2(\mathrm{ads})} \\
& \mathrm{e}_{\mathrm{CB}}{ }^{-}+\mathrm{O}_{2} \stackrel{h v, \text { cat }}{\longrightarrow} \mathrm{O}_{2}^{\cdot-} \\
& 2 \mathrm{H}^{+}+\mathrm{e}_{\mathrm{CB}}^{-}+\mathrm{O}_{2}^{\cdot-} \stackrel{h v, \text { cat }}{\longrightarrow} \mathrm{H}_{2} \mathrm{O}_{2(\mathrm{ads})} \\
& 2 \mathrm{H}_{2} \mathrm{O}+2 h_{\mathrm{VB}}+\stackrel{h v, \text { cat }}{\longrightarrow} \mathrm{H}_{2} \mathrm{O}_{2(\mathrm{ads})}+2 \mathrm{H}^{+} \\
& \mathrm{RH}+\mathrm{H}^{+}+\mathrm{O}_{2}{ }^{\bullet-} \rightarrow \mathrm{H}_{2} \mathrm{O}_{2}+\mathrm{R}^{\bullet} \\
& \mathrm{H}_{2} \mathrm{O}_{2} \rightarrow \frac{1}{2} \mathrm{O}_{2}+\mathrm{H}_{2} \mathrm{O} \\
& \Delta G=-98.0 \mathrm{~kJ} \mathrm{~mol}^{-1}
\end{aligned}
$$

Reaction 3 is known to be a source for $\mathrm{H}_{2} \mathrm{O}_{2}$ when $\mathrm{TiO}_{2}$ is irradiated in the presence of $\mathrm{O}_{2}$. On anatase, the main oxygen reduction product is hydrogen peroxide, whereas on rutile the main product is superoxide ion. ${ }^{21}$ Graetzel speculated that on anatase reaction 3 proceeds in two one-electron steps with free superoxide radicals as intermediates (eqs 4/5). ${ }^{9}$ Using electrochemical data, Augustinsky could show that for anatase $\mathrm{TiO}_{2}$ (but not for rutile) two-electron oxidation of water (eq 6) does 

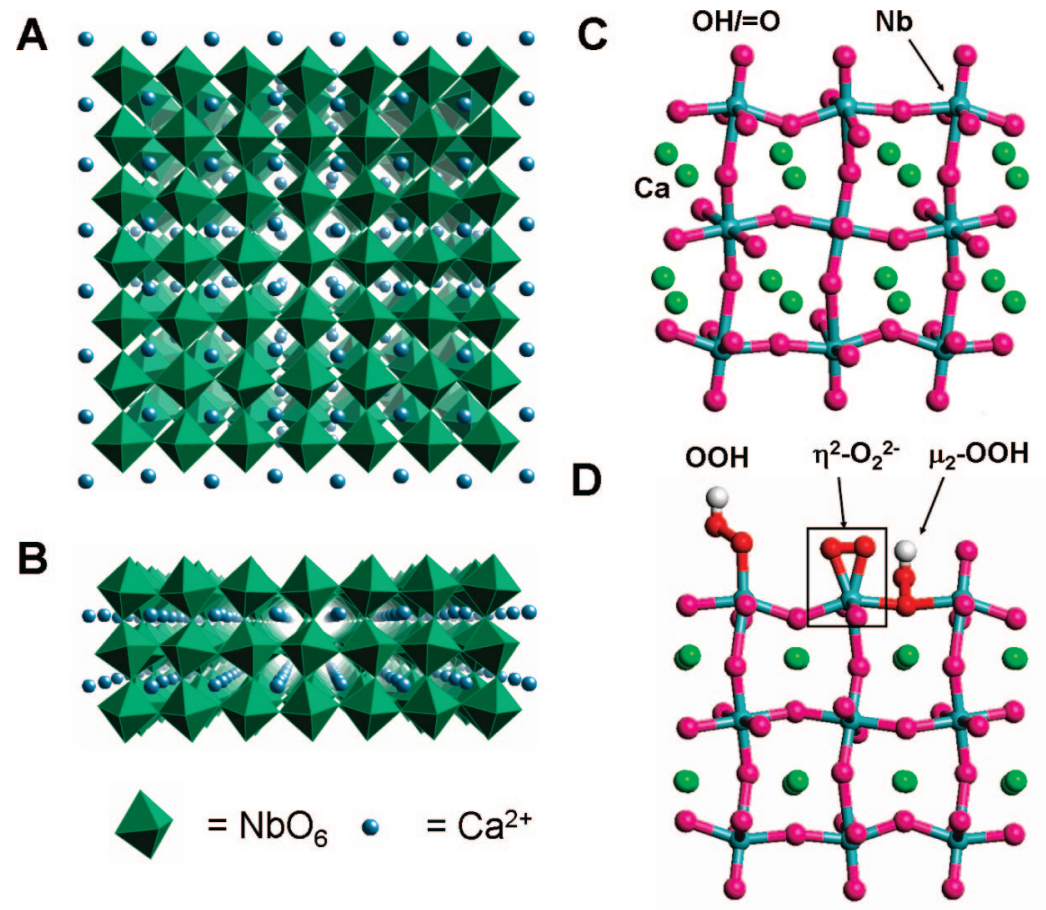

Figure 1. Crystallographic structure of a single $\mathrm{TBA}\left[\mathrm{Ca}_{2} \mathrm{Nb}_{3} \mathrm{O}_{10}\right]$ nanosheet viewed (A) along and (B) perpendicular to the surface normal. (C) Ball and stick model of a layer fragment (side view). The nanosheet surfaces are terminated by $\mathrm{Nb}=\mathrm{O}$ and $\mathrm{Nb}-\mathrm{O}^{-}$groups that can interact with the surrounding water. (D) Possible coordination modes of peroxide to nanosheet surface. The framed coordination mode is observed.

occur. ${ }^{22,23}$ He suggested that the peroxide would bind either as side-on $\eta^{2}$-ligand or as terminal HOO- ligand to a Ti surface ion, or as $\mu_{2}-\eta^{2}$-ligand bridging between two adjacent Ti surface sites.

Here we describe our results of an investigation of the mechanism of photochemical water conversion using nanosheets derived from the known photochemical catalyst $\mathrm{KCa}_{2} \mathrm{Nb}_{3} \mathrm{O}_{10}$ $\left(E_{\mathrm{G}}=3.3-3.5 \mathrm{eV}\right) .^{5,12,24-28}$ As we reported before, dispersions of individual nanosheets are able to evolve $\mathrm{H}_{2}$ from water under UV light, but no oxygen. ${ }^{29-31}$ We now find that hydrogen evolution with the niobate sheets is coupled with stoichiometric formation of peroxide, according to eq 2. This peroxide does not form via reduction of $\mathrm{O}_{2}$ (eq 3), since irradiation experiments conducted in the presence of $\mathrm{O}_{2}$ mostly lead to free $\mathrm{H}_{2} \mathrm{O}_{2}$ and only to small amounts of coordinated peroxide. According to vibrational spectra, the peroxide is present as side-on bound ligand on the surface-Nb sites (Figure 1D). Our findings are important because they shed further light on the inability of certain catalysts to cleave water into $\mathrm{H}_{2}$ and $\mathrm{O}_{2}$, and because they confirm reaction 2 as a water splitting pathway that leads to $\mathrm{H}_{2} \mathrm{O}_{2}$ and $\mathrm{H}_{2}$. Hydrogen peroxide generated in this way could be of potential value as a fuel according to eq 8 .

\section{Experimental Section}

Materials. $o$-Tolidine $(95 \%)$ was obtained from Acros Organics and was purified according to literature procedures. ${ }^{32}$ $\mathrm{H}_{2}{ }^{18} \mathrm{O}$ water (>98\%) was received from Medical Isotopes, Incorporated. Methanol was received from Fisher Scientific. All water used was purified by a Nanopure II system to a resistivity of $>18 \mathrm{M} \Omega \mathrm{cm}$.

TBA $\left[\mathrm{Ca}_{2} \mathbf{N b}_{3} \mathrm{O}_{10}\right]$ Synthesis. The Dion-Jacobsen phase $\mathrm{HCa}_{2} \mathrm{Nb}_{3} \mathrm{O}_{10}$ was synthesized according to literature procedures. ${ }^{33}$ This product was delaminated by treatment with a 20 mol excess of $\mathrm{TBA}(\mathrm{OH})$, resulting in individually dispersed TBA $\left[\mathrm{Ca}_{2} \mathrm{Nb}_{3} \mathrm{O}_{10}\right]$ nanosheets. ${ }^{34}$ Exfoliated nanosheets were stored in aqueous solution at $\mathrm{pH}=11$ to discourage restacking. Solution concentrations were $0.15 \mathrm{M}$ for nanosheets and $1.0 \mathrm{M}$ for $\mathrm{TBA}(\mathrm{OH})$. Aliquots containing $100 \mathrm{mg}$ of nanosheets were diluted to $50 \mathrm{~mL}$ with water before catalytic measurements.

Pt-TBA $\left[\mathrm{Ca}_{2} \mathrm{Nb}_{3} \mathrm{O}_{10}\right]$ Synthesis. Platinum nanoparticles were grown on the surface of $\mathrm{TBA}\left[\mathrm{Ca}_{2} \mathrm{Nb}_{3} \mathrm{O}_{10}\right]$ by photodeposition as described earlier. ${ }^{27}$ Samples in this study contained 3 wt $\%$ of the platinum cocatalyst, as in previous preparations. ${ }^{29,31}$ The product, Pt-TBA $\left[\mathrm{Ca}_{2} \mathrm{Nb}_{3} \mathrm{O}_{10}\right]$, was collected by centrifugation and washed twice with $50 \mathrm{~mL}$ aliquots of water.

Reaction with $\mathrm{H}_{2} \mathrm{O}_{2}$. A $25 \mathrm{mg}$ sample of TBA $\left[\mathrm{Ca}_{2} \mathrm{Nb}_{3} \mathrm{O}_{10}\right]$ was diluted to $10 \mathrm{~mL}$ in a $0.2 \mathrm{M}$ solution of $\mathrm{H}_{2} \mathrm{O}_{2}$. The solution was shaken and left overnight before collection of the precipitate, which began to form after $3 \mathrm{~h}$.

Irradiation and $\mathrm{H}_{2} / \mathrm{O}_{2}$ Measurement. Solutions of catalysts were irradiated simultaneously with four $175 \mathrm{~W}$ low-pressure mercury lamps that delivered a combined quantum flux of 5.82 $\times 10^{-7} \mathrm{~mol} / \mathrm{s}$ inside the test flask as measured by ferrioxalate actinometry. ${ }^{35}$ Quantum efficiencies were calculated $(\mathrm{QE}=$ $\left.2 \cdot\left[\mathrm{H}_{2}\right] / \mathrm{I}\right)$ from the quantum flux of the irradiation system (I) and the average rate of $\mathrm{H}_{2}$ evolution in moles per second. A $100 \mathrm{~mL}$ quartz flask, directly connected to a gas chromatograph via a gas valve, was filled with $50 \mathrm{~mL}$ of aqueous solution containing $100 \mathrm{mg}$ of catalyst. The flask was evacuated and purged three times with argon gas to remove any dissolved gases in the solution. The flask was irradiated while stirring, and samples were periodically withdrawn directly from the flask into a gas chromatograph. For $\mathrm{O}_{2}$ adsorption measurements, $2 \mathrm{~mL}$ of $\mathrm{O}_{2}$ gas was injected into the atmosphere above the flask through a rubber septum using a gas-tight syringe.

Assay with $\boldsymbol{o}$-Tolidine. Hydrogen peroxide measurements were performed on $2.0 \mathrm{~mL}$ aliquots of the catalyst suspension that were removed after varying periods of irradiation. For each test, a $0.5 \mathrm{~mL}$ volume of $1 \% \mathrm{o}$-tolidine in $0.1 \mathrm{M} \mathrm{HCl}$ was added to the suspension along with $1.0 \mathrm{~mL}$ of colloidal platinum 

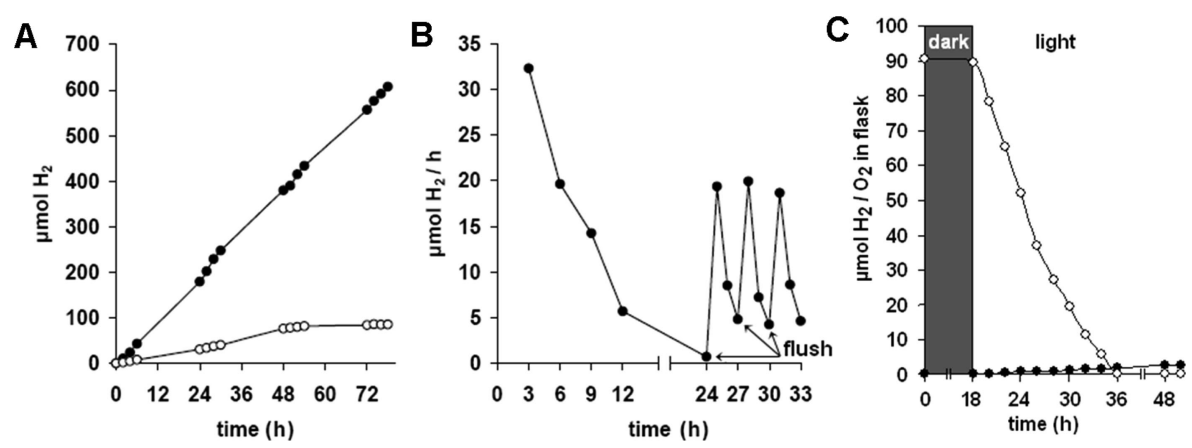

Figure 2. (A) $\mathrm{H}_{2}$ evolution data for water $(\mathrm{O})$ and $20 \%$ aqueous methanol (-) using $100 \mathrm{mg}$ nanosheets. (B) Rate of $\mathrm{H}_{2}$ evolution from Pt$\left[\mathrm{HCa}_{2} \mathrm{Nb}_{3} \mathrm{O}_{10}\right]$ as a function of time. Arrows indicate evacuation to 20 torr followed by purging with $\mathrm{Ar}$ gas. $(\mathrm{C})$ Evolution of $\mathrm{H}_{2}(\mathbf{O})$ and of added $\mathrm{O}_{2}(\mathrm{O})$ under irradiation.

prepared as explained previously. ${ }^{29}$ This mixture was allowed to react for $5 \mathrm{~min}$. A blue color indicative of oxidized $o$-tolidine evolved within $30 \mathrm{~s}$. A volume of $0.5 \mathrm{~mL}$ of $1 \mathrm{M} \mathrm{HCl}$ was then added, generating a yellow color. The product was centrifuged, and the supernatant was removed and diluted to $10 \mathrm{~mL}$ with water. The absorbance of the solution was then measured with a UV-vis spectrophotometer. The instability of the product at room temperature (complete decomposition after $\sim 1 \mathrm{~h}$ ) required consistent reaction periods for quantitative measurement. Solutions of nonirradiated TBA $\left[\mathrm{Ca}_{2} \mathrm{Nb}_{3} \mathrm{O}_{10}\right]$ did not turn blue after addition of $o$-tolidine and were faintly yellow after addition of $\mathrm{HCl}$. A calibration curve was obtained by reacting solutions of $\mathrm{H}_{2} \mathrm{O}_{2}$, ranging in concentration from $8.8 \times 10^{-5}$ to $1.3 \times 10^{-3}$ $\mathrm{M}$, in place of the nanosheet sample, yielding an extinction coefficient of $932 \mathrm{M}^{-1} \cdot \mathrm{cm}^{-1}$, which compares well to previously determined values. ${ }^{18,20}$

IR and Raman Sample Preparation. Samples of nanosheets were centrifuged from solution, and the precipitates were collected. Thin layers of precipitate were dried on a $\mathrm{KBr}$ plate for IR measurements, or a glass slide for Raman measurements, and promptly analyzed.

NMR Sample Preparation. Samples of irradiated nanosheets were dried under vacuum. Dried residues were dissolved in $\mathrm{D}_{2} \mathrm{O}$. Samples were added to an NMR tube, taking care to not include any solids.

Instrumentation. Gas samples from the reaction space above the irradiated solutions were injected into a gas chromatograph employing Ar as the carrier gas. Sample components were separated with a Supelco molecular 60/80 sieve $5 \AA$ column and detected with a thermal conductivity detector (TCD). UV/ vis spectra were collected using an Ocean Optics DH2000 light source and HR2000 CG-UV-NIR spectrometer. Infrared spectra were collected with a Tensor 27 FT-IR spectrometer from Bruker Optics. Raman spectra were collected using a Renishaw RM1000 microspectrometer. A Fisher Scientific Marathon 21000 centrifuge at $13750 \mathrm{rpm}$ was employed for centrifugation. $\mathrm{H}^{1}$-NMR spectra were obtained with either a Varian Inova 400 $\mathrm{MHz}$ or Bruker Avance $600 \mathrm{MHz}$ NMR spectrometer, for catalysts dispersed in $\mathrm{D}_{2} \mathrm{O}$, and with calibration against tetramethylsilane.

\section{Results and Discussion}

The time course of hydrogen evolution from a UV-irradiated TBA $\left[\mathrm{Ca}_{2} \mathrm{Nb}_{3} \mathrm{O}_{10}\right]$ sample suspended in aqueous methanol or water is shown in Figure $2 \mathrm{~A}$ (values given in Table 1). In methanol solution, steady evolution of $\mathrm{H}_{2}$ takes place over $72 \mathrm{~h}$ at nearly constant rate. If $\mathrm{TBA}\left[\mathrm{Ca}_{2} \mathrm{Nb}_{3} \mathrm{O}_{10}\right]$ is irradiated in water, substantially less $\mathrm{H}_{2}$ is formed, and after $48 \mathrm{~h}$ the $\mathrm{H}_{2}$ rate begins
TABLE 1: $\mathbf{H}_{2}$ Evolution Data

\begin{tabular}{lcccc}
\hline & \multicolumn{2}{c}{$\begin{array}{c}\text { nanosheets } \\
\text { in } \mathrm{H}_{2} \mathrm{O}\end{array}$} & \multicolumn{2}{c}{$\begin{array}{c}\text { nanosheets in } \\
20 \% \mathrm{MeOH}\end{array}$} \\
\hline initial pH & \multicolumn{2}{c}{8.3} & \multicolumn{2}{c}{10.6} \\
irradiation time & $0-48 \mathrm{~h}$ & $48-78 \mathrm{~h}$ & $0-48 \mathrm{~h}$ & $48-78 \mathrm{~h}$ \\
$\mathrm{H}_{2}(\mu \mathrm{mol})$ & 76.2 & 9.26 & 379.8 & 227.7 \\
$\mathrm{H}_{2}$ rate $(\mu \mathrm{mol} / \mathrm{h})$ & 1.59 & 0.31 & 7.91 & 7.59 \\
$\mathrm{QE}(\%)$ & 0.15 & 0.03 & 0.76 & 0.73
\end{tabular}

to drop to $20 \%$ of the initial rate. For TBA $\left[\mathrm{Ca}_{2} \mathrm{Nb}_{3} \mathrm{O}_{10}\right]$ modified with 3 wt $\% \mathrm{Pt}$ particles, the $\mathrm{H}_{2}$ rate from water diminishes after $9 \mathrm{~h}$ of irradiation. ${ }^{29}$ However, evacuating the atmosphere above the solution and then flushing with Ar gas temporarily restores the $\mathrm{H}_{2}$ evolution rate to $60 \%$ of the original activity, as shown in Figure 2B.

Considering previous work for $\mathrm{TiO}_{2},{ }^{9-11,18-20}$ we suspected that deactivation of the catalyst occurred because of the accumulation of hydrogen peroxide on the catalyst surface. To determine any peroxides formed in the reaction, nanosheets were titrated with the redox indicator $o$-tolidine in the presence of colloidal Pt as a catalyst, as described previously. ${ }^{11,18,20}$ The reaction at $\mathrm{pH}>3$ initially leads to a quinone-diimine complex (Supporting Information) with an absorbance maximum at 625 $\mathrm{nm}$ corresponding to a blue color. When $o$-tolidine is added to a suspension of catalyst $(\mathrm{pH}=10.5)$ that had been irradiated for $6 \mathrm{~h}$, this blue color develops within $30 \mathrm{~s}$. Nonirradiated samples do not show the blue color, and neither does the supernatant of irradiated samples after removal of the catalyst. This shows that the $\mathrm{H}_{2} \mathrm{O}_{2}$ is generated photochemically and that it is associated with the catalyst. After acidification of the solution to $\mathrm{pH}<3$, the amount of peroxide can be quantified using the $438 \mathrm{~nm}$ absorbance of the free diimine (Figure 3 and Table 2). It can be seen that the intensity of the absorbance peak increases with extended irradiation periods as more peroxide was generated. After $6 \mathrm{~h}$ of irradiation, one determines a value of $8.97 \pm 1.24 \mu \mathrm{mol}$, and after $24 \mathrm{~h}$ this amount increases to $30.46 \pm 3.40 \mu \mathrm{mol}$. Nonirradiated nanosheet samples were also tested and possessed a weak absorbance at $438 \mathrm{~nm}$, which should be attributed to trace amounts of peroxide developed during sample storage.

Evolution of $\mathrm{H}_{2}$ in the gas phase was measured concurrently with peroxide titration. After 6,12 , or $24 \mathrm{~h}$ of irradiation, a near 1:1 stoichiometric $\mathrm{H}_{2}: \mathrm{H}_{2} \mathrm{O}_{2}$ ratio is observed, in agreement with the electron balance of the reaction. This establishes reaction 2 as the net catalytic process in water.

IR and Raman spectroscopy were employed to further characterize the photogenerated peroxide (Figure 4 and Table 3). Peaks at 580, 778, and $940 \mathrm{~cm}^{-1}$ in the IR spectrum and their counterparts in the Raman spectrum were present on 

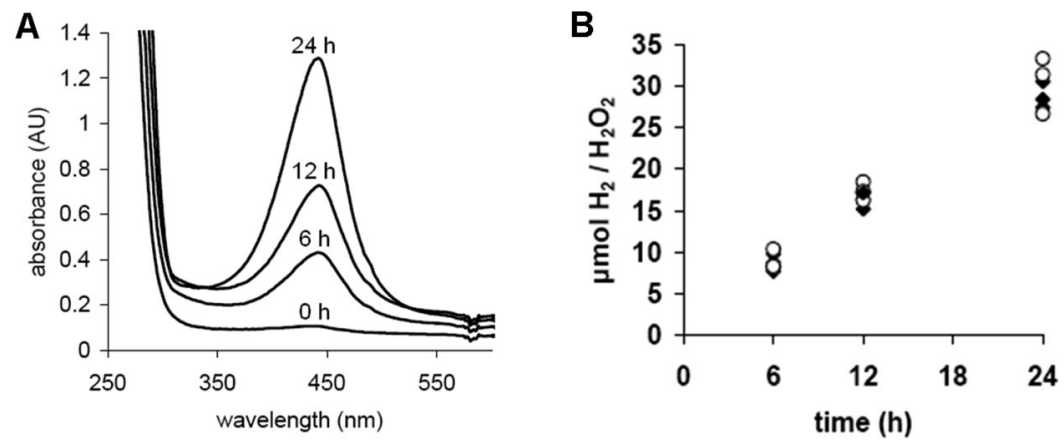

Figure 3. (A) UV-vis absorption spectra showing absorbance at $438 \mathrm{~nm}$ of the protonated diimine as irradiation times were increased. (B) Time-resolved $\mathrm{H}_{2}(\bullet)$ and $\mathrm{H}_{2} \mathrm{O}_{2}(\mathrm{O})$ evolution data.

TABLE 2: $\mathrm{H}_{2} / \mathrm{H}_{2} \mathrm{O}_{2}$ Stoichiometry ${ }^{a}$

\begin{tabular}{ccrc}
\hline irradiation time $(\mathrm{h})$ & \multicolumn{1}{c}{$\mathrm{H}_{2}(\mu \mathrm{mol})$} & $\mathrm{H}_{2} \mathrm{O}_{2}(\mu \mathrm{mol})$ & ratio $\mathrm{H}_{2}: \mathrm{H}_{2} \mathrm{O}_{2}$ \\
\hline 6 & $8.76 \pm 1.04$ & $8.97 \pm 1.24$ & $1: 0.98$ \\
12 & $16.22 \pm 1.39$ & $17.70 \pm 1.13$ & $1: 0.92$ \\
24 & $28.81 \pm 1.59$ & $30.46 \pm 3.40$ & $1: 0.94$
\end{tabular}

${ }^{a}$ All values are based on three separate measurements for each irradiation time.

nanosheets recovered from both irradiated and nonirradiated samples. Based on a comparison with $\mathrm{KCa}_{2} \mathrm{Nb}_{3} \mathrm{O}_{10}$, and $\mathrm{HCa}_{2} \mathrm{Nb}_{3} \mathrm{O}_{10}$ (Figure 4A), the bands at 940 and $778 \mathrm{~cm}^{-1}$ were assigned to $\mathrm{Nb}=\mathrm{O}$ and $\mathrm{Nb}-\mathrm{OH}$ on the sheet surface. As surface sites, these bonds are expected to react most sensitively to cation exchange and protonation.

The band at $580 \mathrm{~cm}^{-1}$ was assigned to $\mathrm{Nb}-\mu_{2}-\mathrm{O}$ bonds within the sheets. ${ }^{36,37}$ This represents the majority of $\mathrm{Nb}-\mathrm{O}$ bonds in the material, giving this absorption the strongest intensity in the spectrum. The broadness of this peak results from inequivalency of the $\mathrm{Nb}-\mathrm{O}$ bonds that belong to surface and buried $\mathrm{Nb}-\mu_{2}-\mathrm{O}$ sites (Figure 1C). After irradiation, new peaks at 423 , 482 , and $873 \mathrm{~cm}^{-1}$ appeared in the IR spectrum and a set of corresponding peaks in the Raman spectrum (black traces in Figure $4 \mathrm{~B}, \mathrm{C})$. The band at $873 \mathrm{~cm}^{-1}$ was assigned to $v[\mathrm{O}-\mathrm{O}]$ stretching of a peroxo group, which is generally found in the $850-910 \mathrm{~cm}^{-1}$ range when bound to metal ions. ${ }^{38-40}$ The peak at $482 \mathrm{~cm}^{-1}$ can be attributed to an asymmetric $\nu_{\mathrm{a}}\left[\mathrm{Nb}\left(\mathrm{O}_{2}\right)\right]$ stretch of the peroxo group, given its relative weakness when compared to the strong corresponding peak at $481 \mathrm{~cm}^{-1}$ in the Raman spectrum. Thus, the peak at $423 \mathrm{~cm}^{-1}$ in the IR spectrum is likely a symmetric $v_{\mathrm{S}}\left[\mathrm{Nb}\left(\mathrm{O}_{2}\right)\right]$ stretch. Symmetric and asymmetric $v\left[\mathrm{Nb}\left(\mathrm{O}_{2}\right)\right]$ stretches are generally found to absorb in the range of $430-520 \mathrm{~cm}^{-1} \cdot 38,40$

In order to verify these assignments, we also prepared peroxide-coated nanosheets by direct reaction of TBA$\left[\mathrm{Ca}_{2} \mathrm{Nb}_{3} \mathrm{O}_{10}\right]$ with $0.2 \mathrm{M} \mathrm{H}_{2} \mathrm{O}_{2}$. The peroxide derivative begins to precipitate from such a mixture after $3 \mathrm{~h}$. It can be seen that the vibrational spectra recorded for this material (red traces in Figure 4B, C) are very similar to those obtained for the irradiated nanosheets. However, all new peak bands are stronger than for the irradiated sample, suggesting that the peroxide concentration on the nanosheets is higher. Also noticeable now is a small blue shift of the $\mathrm{Nb}-\mathrm{OH}$ and $\mathrm{Nb}-\mu_{2}-\mathrm{O}$ bands by $\sim 15 \mathrm{~cm}^{-1}$, exposing a shoulder in the $\mathrm{Nb}-\mu_{2} \mathrm{O}$ band at $557 \mathrm{~cm}^{-1}$. While both $\mathrm{Nb}=\mathrm{O}$ and $\mathrm{Nb}-\mathrm{OH}$ bands are weakened in the IR, the Raman shows the $\mathrm{Nb}-\mathrm{OH}$ band at nearly unchanged intensity. The selective weakening of the $\mathrm{Nb}=\mathrm{O}$ band indicates that the $\mathrm{H}_{2} \mathrm{O}_{2}$ selectively coordinates to the former $\mathrm{Nb}=\mathrm{O}$ sites.

Most of the spectral changes caused by $\mathrm{H}_{2} \mathrm{O}_{2}$ coordination can be reversed upon heating the treated nanosheets to $450{ }^{\circ} \mathrm{C}$.
IR spectra shown in Figure 4D reveal a disappearing $v(\mathrm{O}-\mathrm{O})$ band at $873 \mathrm{~cm}^{-1}$ as the temperature is increased. The $v(\mathrm{Nb}=\mathrm{O})$ band, which had disappeared upon treatment with $\mathrm{H}_{2} \mathrm{O}_{2}$, reappears, and concurrently the $v(\mathrm{Nb}-\mathrm{OH})$ band shifts back to its original position of $778 \mathrm{~cm}^{-1}$. The $v\left(\mathrm{Nb}-\mu_{2}-\mathrm{O}\right)$ band at 589 $\mathrm{cm}^{-1}$ (not shown) and the $\mathrm{Nb}=\mathrm{O}$ band at $928 \mathrm{~cm}^{-1}$ appear slightly shifted from their original positions. This indicates that while most of the surface-bound peroxide is thermally decomposed and replaced by $\mathrm{Nb}=\mathrm{O}$ bonds, some distortion remains that shifts these bands. The high stability of peroxide seems to be the primary reason for the inability of the niobate nanosheets to catalyze the overall water splitting reaction (eq 1).

To elucidate the origin of the coordinated peroxide and to confirm peak assignments, we also performed a series of experiments in $>98 \% \mathrm{H}_{2}{ }^{18} \mathrm{O}$ water. IR and Raman spectra for TBA $\left[\mathrm{Ca}_{2} \mathrm{Nb}_{3} \mathrm{O}_{10}\right]$ that had been stored in ${ }^{18} \mathrm{O}$ water for 1 week and then irradiated for $20 \mathrm{~h}$ are shown in Figure 4B, C (blue trace). The IR spectrum shows a reduction of the $\mathrm{Nb}-\mathrm{OH}$ and $\mathrm{Nb}=\mathrm{O}$ bands, and the appearance of a broad peak at $879 \mathrm{~cm}^{-1}$ belonging to the $v(\mathrm{O}-\mathrm{O})$ mode. The peak is broadened because partial isotopic substitution produces three independent species ${ }^{18} \mathrm{O}-{ }^{18} \mathrm{O},{ }^{18} \mathrm{O}-{ }^{16} \mathrm{O}$, and ${ }^{16} \mathrm{O}-{ }^{16} \mathrm{O}$, with deviating absorption bands $\left(823,848\right.$, and $873 \mathrm{~cm}^{-1}$, respectively) in this area. Accordingly, the Raman spectrum also shows a broad $\mathrm{O}-\mathrm{O}$ band at $890-840 \mathrm{~cm}^{-1}$, and two broadened bands at 433 and $473 \mathrm{~cm}^{-1}$ for the symmetric and asymmetric $v_{\mathrm{a}}\left[\mathrm{Nb}\left({ }^{18 / 16} \mathrm{O}_{2}\right)\right]$ stretching vibrations of a side-on coordinated peroxide.

If the nanosheets are kept in $\mathrm{H}_{2}{ }^{18} \mathrm{O}$ for 1 week, but not irradiated, the $v_{\mathrm{a}}\left[\mathrm{Nb}\left({ }^{18 / 16} \mathrm{O}_{2}\right)\right]$ bands are absent in the Raman spectrum (green trace in Figure 4B). However, the broad band at $890-840 \mathrm{~cm}^{-1}$ remains, which we attribute to contamination of the recycled $\mathrm{H}_{2}{ }^{18} \mathrm{O}$ with peroxide from previous experiments. Simple storage of the nanosheets in $\mathrm{H}_{2}{ }^{18} \mathrm{O}$ also causes the $\mathrm{Nb}-\mu_{2}-\mathrm{O}$ bands to shift to lower wavenumbers, indicating isotopic exchange of even the bridging ${ }^{16} \mathrm{O}$ ions with ${ }^{18} \mathrm{O}$. Thermal isotope exchange of terminal and bridging $\mathrm{O}$ has been previously observed for the Lindqvist cluster ion $\left[\mathrm{Nb}_{6} \mathrm{O}_{16}\right]^{6-}$, which contains $1 \mu_{6}-\mathrm{O}, 6$ terminal $\mathrm{O}$, and $12 \mu_{2}$-O sites. ${ }^{41} \mathrm{In}$ this case, room-temperature ${ }^{17} \mathrm{O}$-nuclear magnetic resonance reveals that the terminal and the $\mu_{2}$-oxygen ions can be exchanged over the course of hours to days, with rates strongly dependent on $\mathrm{pH}$.

There are several possibilities for $\mathrm{H}_{2} \mathrm{O}_{2}$ to bind to the nanosheets (Figure 1D), including end-on, $\eta^{2}$, or $\mu_{2}-\eta^{1}$-bridging modes. A $\mu_{2}-\eta^{2}$ mode, in which one $\mathrm{O}_{2}{ }^{2-}$ ion connects two adjacent metal ions, has been suggested for $\mathrm{TiO}_{2},{ }^{18}$ but is impossible for $\mathrm{HCa}_{2} \mathrm{Nb}_{3} \mathrm{O}_{10}$ due to the larger $\mathrm{Nb}-\mathrm{Nb}$ separation on the nanosheet surface. Side-on coordinated $\mathrm{O}_{2}{ }^{2-}$ is frequently observed in molecular $\mathrm{Nb}(5+)$ complexes, including $\left[\mathrm{Nb}\left(\mathrm{O}_{2}\right) \mathrm{F}_{5}\right]^{2-}$ ${ }^{42}\left[\mathrm{Nb}\left(\mathrm{O}_{2}\right)_{3}\right.$ (phen) $),{ }^{43}$ and $\left[\mathrm{Nb}\left(\mathrm{O}_{2}\right)_{2}(\right.$ tart $\left.)\right](\text { tart }=\text { tartrate })^{44}$ which 


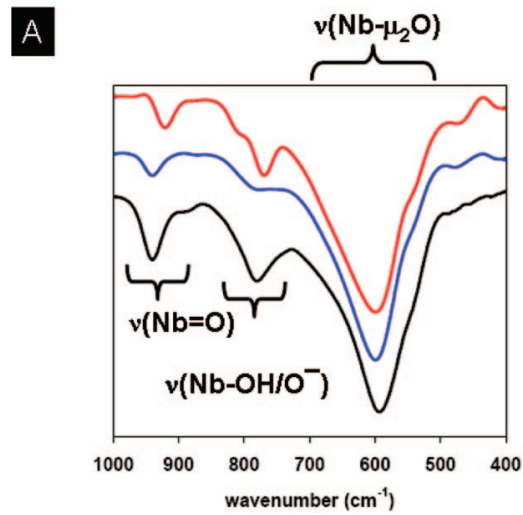

B
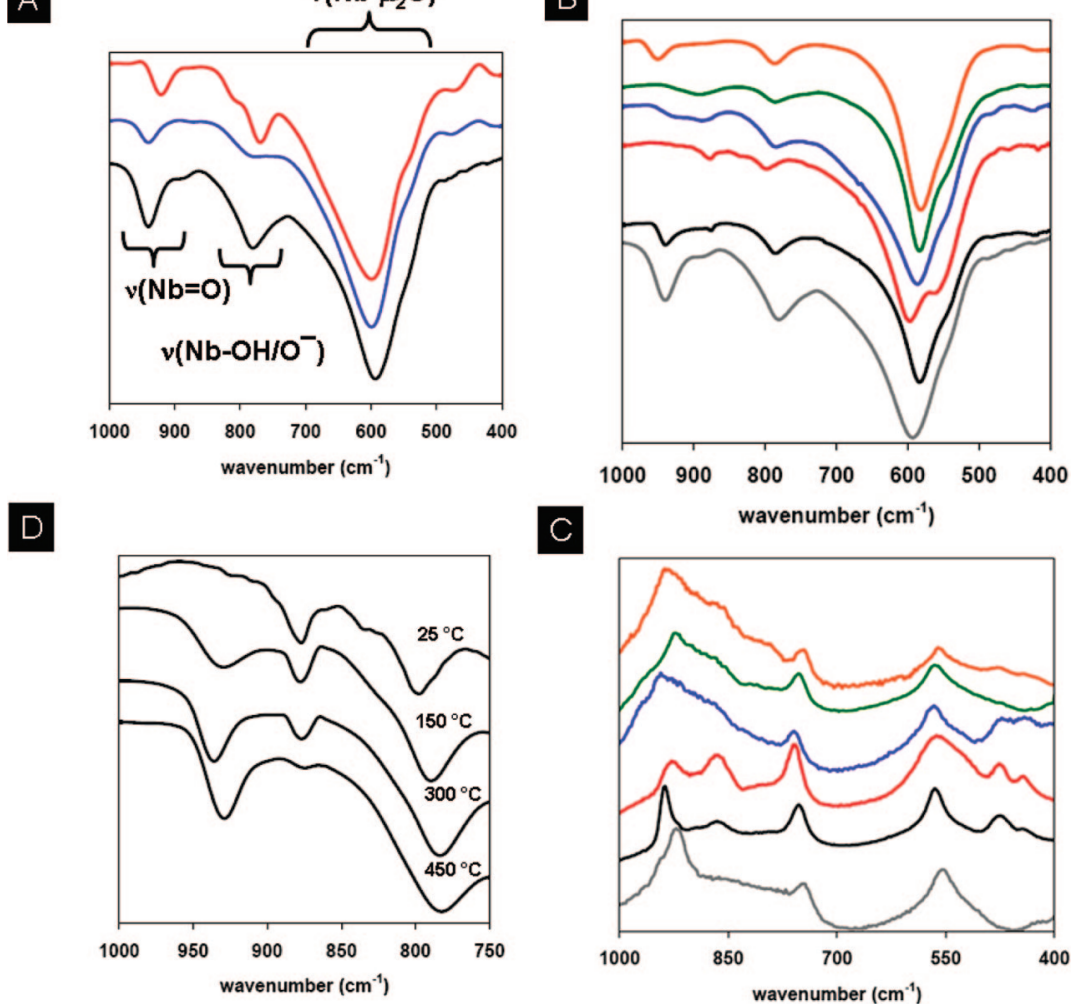

C

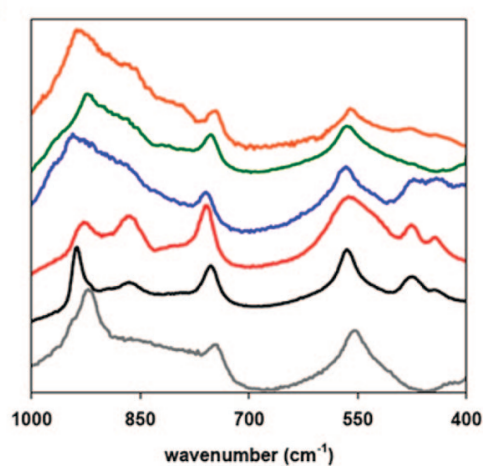

Figure 4. (A) Infrared spectra of $\mathrm{KCa}_{2} \mathrm{Nb}_{3} \mathrm{O}_{10}$ (top), $\mathrm{HCa}_{2} \mathrm{Nb}_{3} \mathrm{O}_{10}$ (middle), and $\mathrm{TBACa}_{2} \mathrm{Nb}_{3} \mathrm{O}_{10}$ (bottom). (B) IR and (C) Raman spectra of TBACa $\mathrm{Nb}_{3} \mathrm{O}_{10}$ before (gray) and after (black) irradiation in $\mathrm{H}_{2} \mathrm{O}$, after storage (green) and irradiation (blue) in $\mathrm{H}_{2}{ }^{18} \mathrm{O}$, after treatment with $\mathrm{H}_{2} \mathrm{O}_{2}$ (red), and after irradiation in air (orange). (D) IR showing thermal removal of $\mathrm{H}_{2} \mathrm{O}_{2}$.

TABLE 3: IR and Raman Vibrational Data ${ }^{a}$

\begin{tabular}{|c|c|c|c|c|c|c|c|c|c|c|c|c|}
\hline & \multicolumn{2}{|c|}{$v(\mathrm{Nb}=\mathrm{O})$} & \multicolumn{2}{|c|}{$v(\mathrm{Nb}-\mathrm{OH})$} & \multicolumn{2}{|c|}{$v(\mathrm{Nb}-\mathrm{O})$} & \multicolumn{2}{|c|}{$v(\mathrm{O}-\mathrm{O})$} & \multicolumn{2}{|c|}{$v_{\mathrm{a}}\left[\mathrm{Nb}\left(\mathrm{O}_{2}\right)\right]$} & \multicolumn{2}{|c|}{$v_{\mathrm{s}}\left[\mathrm{Nb}\left(\mathrm{O}_{2}\right)\right]$} \\
\hline & IR & $\overline{\text { Raman }}$ & IR & Raman & IR & Raman & IR & Raman & IR & Raman & IR & Raman \\
\hline irr. & 940 & 939 & 778 & 758 & 580 & 571 & 873 & 870 & 482 & 481 & 423 & 441 \\
\hline react. with $\mathrm{H}_{2} \mathrm{O}_{2}$ & - & 934 & 793 & 762 & 594 & 566 & 872 & 871 & 458 & 481 & 418 & 448 \\
\hline
\end{tabular}

${ }^{a}$ Repeated collection of spectra showed variance in the location of Raman peaks $\pm 8 \mathrm{~cm}^{-1}$, while IR peaks varied $\pm 3 \mathrm{~cm}^{-1}$.

feature up to three peroxide ligands and seven/eight coordinate $\mathrm{Nb}$ ions*. For $\mathrm{HCa}_{2} \mathrm{Nb}_{3} \mathrm{O}_{10}$, the vibrational spectra discussed above favor the $\mathrm{Nb}-\eta^{2}-\mathrm{O}_{2}$ mode, because it is the only mode that gives rise to the asymmetrical and symmetrical $v\left[\mathrm{Nb}\left(\mathrm{O}_{2}\right)\right]$ bands observed around $420-480 \mathrm{~cm}^{-1}$. Also, only this mode gives a nonpolar $\mathrm{O}-\mathrm{O}$ bond, which is weakly IR-active and strongly Raman-active, as observed in Figure 4B, C (red traces). Based on the relative signal intensities of the $\mathrm{Nb}=\mathrm{O}$ and $\mathrm{Nb}-\mathrm{OH}$ Raman bands after irradiation or treatment with $\mathrm{H}_{2} \mathrm{O}_{2}$ (gray, black, red traces in Figure 4C), there seems to be a preference for the peroxide ions to coordinate to $\mathrm{Nb}$ ions of the $\mathrm{Nb}=\mathrm{O}$ sites. This ligand substitution could occur without disturbing the charge balance of the $\mathrm{Nb}=\mathrm{O}$ group and could be thought of as a thermodynamically controlled acid-base equilibrium in which the more acidic $\mathrm{H}_{2} \mathrm{O}_{2}\left(\mathrm{p} K_{\mathrm{A}}=11.6\right)$ displaces the less acidic water $\left(\mathrm{p} K_{\mathrm{A}}=15.7\right)$ from its salt. By contrast, incorporation of the peroxide at the $\mathrm{Nb}-\mathrm{OH}$ sites would lead to a buildup of negative charge or produce a terminal $\mathrm{Nb}-\mathrm{OOH}$, which is not observed in the IR. The increase of the coordination number of the $\mathrm{Nb}-\eta^{2}-\mathrm{O}_{2}$ sites from six to seven should cause a local distortion of the resulting $\mathrm{Nb}\left(\mu_{2}-\mathrm{O}\right)_{6}\left(\mathrm{O}_{2}\right)$ polyhedron and adjacent $\mathrm{NbO}_{6}$ octahedra. This might explain the observed shift of the $\mathrm{Nb}-\mu_{2} \mathrm{O}$ stretching bands to higher energy in irradiated or $\mathrm{H}_{2} \mathrm{O}_{2}$-treated nanosheets.
There are two possible routes for the formation of side-on bonded peroxide in this system, either by two-electron oxidation of water (eq 2) or by two-electron reduction of small traces of $\mathrm{O}_{2}$ (eq 3). To distinguish among these pathways, we conducted $\mathrm{O}_{2}$ uptake experiments with the irradiated catalysts in the presence of $\mathrm{O}_{2}$ and analyzed reaction products with vibrational spectroscopy, NMR, and titrations with the redox indicator. The results of the $\mathrm{O}_{2}$ uptake experiment are presented in Figure $2 \mathrm{C}$. Only minor $\mathrm{O}_{2}$ uptake $\left(\sim 1 \mu \mathrm{mol}\right.$ of $\left.\mathrm{O}_{2}\right)$ occurred when the catalyst dispersion was stirred in the dark for $18 \mathrm{~h}$, which should be attributed to dissolution of the gas in the water. Upon irradiation, $\mathrm{O}_{2}$ was removed from the atmosphere at an average rate of $6.3 \mu \mathrm{mol} / \mathrm{h}$ for the first $10 \mathrm{~h}$. This rate slowed from that point to $3.6 \mu \mathrm{mol} / \mathrm{h}$ until all $\mathrm{O}_{2}$ was removed from the system after $18 \mathrm{~h}$ of irradiation. During $\mathrm{O}_{2}$ adsorption, only $2.52 \mu \mathrm{mol}$ of $\mathrm{H}_{2}$ was evolved over $30 \mathrm{~h}$ of irradiation, giving a rate of $0.084 \mu \mathrm{mol} / \mathrm{h}$. This rate is more than 20 times lower than what is observed in the absence of added $\mathrm{O}_{2} \cdot{ }^{31}$ About $6.22 \mu \mathrm{mol}$ of peroxide was detected in the supernatant by $o$-tolidine titration, but only amounts comparable to nonirradiated nanosheets were found associated with the catalyst. When the catalyst suspension was irradiated in air, weak peroxide bands could also be observed in the vibrational spectra (Figure 4B, C, orange traces). 


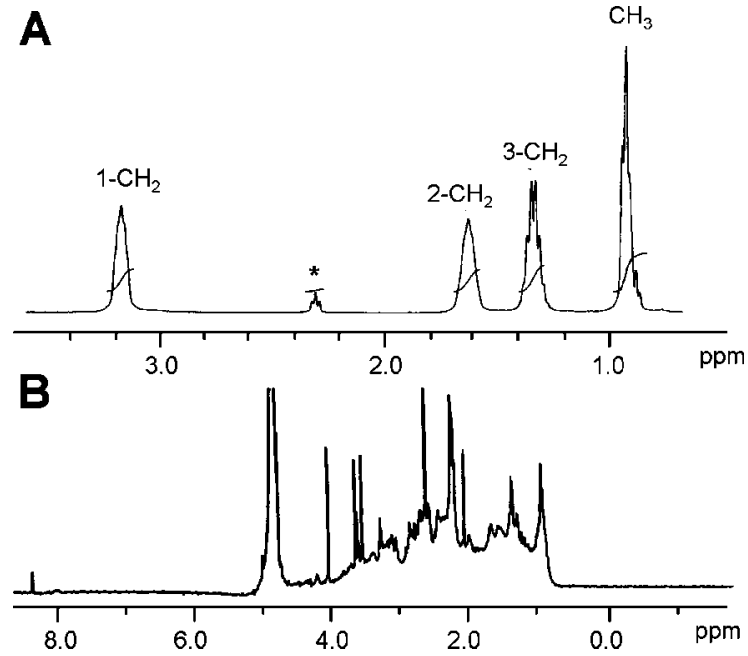

Figure 5. ${ }^{1} \mathrm{H}-\mathrm{NMR}$ spectra $\left(300 \mathrm{MHz}, \mathrm{D}_{2} \mathrm{O}\right)$ of residue from irradiated TBACa ${ }_{2} \mathrm{Nb}_{3} \mathrm{O}_{10}$ suspension: (A) after irradiation in Ar atmosphere and (B) after irradiation in air atmosphere. * indicates impurity.

${ }^{1} \mathrm{H}-\mathrm{NMR}$ spectra collected for the catalyst suspension after irradiation in argon or air atmosphere are shown in Figure 5. Irradiation in the absence of $\mathrm{O}_{2}$ does reveal peaks for the TBA counterion, with only minor downfield shift $(+0.1 \mathrm{ppm})$ compared to a nonirradiated catalyst (spectrum not shown). Samples irradiated in air show a drastically changed spectrum with broad peaks at 4.194-0.908 ppm and a weak peak at 8.338 ppm, which could be indicative of an amide species. Only traces of the original $\mathrm{TBA}^{+}$are preserved, suggesting partial decomposition of the tetrabutylammonium cation under these conditions. This decomposition of the counterion is also supported by the observation that the catalyst precipitates when the irradiation is performed in air, whereas no precipitation occurs in argon atmosphere. TBA decomposition can be explained by assuming that irradiation in air produces superoxide radicals via one-electron reduction of $\mathrm{O}_{2}$ (eq 4) which react with TBA under $\mathrm{H}$ abstraction and $\mathrm{H}_{2} \mathrm{O}_{2}$ formation (eq 7). These reactions are known to be involved in the photochemical remediation of organic waste. ${ }^{45-49}$ Most of the $\mathrm{H}_{2} \mathrm{O}_{2}$ formed in this way would not be associated with the catalyst, while some of it could adsorb to the niobate sheets by direct reaction, as described above. Conversely, irradiation in the absence of air produces side-on coordinated peroxide by two-electron oxidation of water (eq 2), without free radical intermediates.

\section{Conclusion}

The principle conclusions from this work are the following:

1. Niobate nanosheets photocatalytically decompose water stoichiometrically into $\mathrm{H}_{2}$ and $\mathrm{H}_{2} \mathrm{O}_{2}$.

2. The peroxide coordinates as a side-on ligand to the surface $\mathrm{Nb}(5+)$ ions but can be removed by heating the solid catalyst to $450{ }^{\circ} \mathrm{C}$, or, partially, by purging of the catalyst dispersion with $\mathrm{Ar}$ in solution. The high stability of the $\mathrm{Nb}$ - peroxide bond seems to be the reason for the inability of the nanosheets to evolve $\mathrm{O}_{2}$ under irradiation with UV light.

3. Based on $\mathrm{H}_{2}{ }^{18} \mathrm{O}$ studies the peroxide forms by two-electron oxidation of water (eq 6) or by direct reaction of the niobate with $\mathrm{H}_{2} \mathrm{O}_{2}$. The photochemical formation of the peroxide does not seem to involve free radicals, based on the integrity of the TBA counterion.

4. Reaction of the niobate nanosheets with $\mathrm{H}_{2}{ }^{18} \mathrm{O}$ at room temperature leads to isotopic exchange of all $\mathrm{O}$ atoms in the nanosheets over the course of $24 \mathrm{~h}$.
5. Irradiation of the catalyst in the presence of air produces free $\mathrm{H}_{2} \mathrm{O}_{2}$ via reduction of $\mathrm{O}_{2}$ (eq 4). The decomposition of the tetrabutylammonium counterion indicates that free radicals, e.g., superoxide, are involved in this process (eq 7).

Acknowledgment. This work was supported by an Energy Innovation Startup Grant of the California Energy Commission. We thank Alan Hicklin for help with collecting Raman spectra and NEAT ORU for the use of their facilities. We also thank W. R. Griswald VI for collecting NMR spectra.

Note Added in Proof. The newly discovered cluster ion $\left[\mathrm{H}_{3} \mathrm{Nb}_{6} \mathrm{O}_{13}\left(\mathrm{O}(\mathrm{I})_{2}\right)_{6}\right]^{8-}$ contains six side-on bonded peroxide ligands. Ohlin, C. A.; Villa, E. M.; Fettinger, J. C.; Casey, W. H. Angew. Chem. Int. Ed. Engl. 2008, 47 (43), 8251-8254.

Supporting Information Available: Details of the reaction of $o$-tolidine with peroxide. This material is available free of charge via the Internet at http://pubs.acs.org.

\section{References and Notes}

(1) Fujishima, A.; Honda, K. Bull. Chem. Soc. Jpn. 1971, 44, 1148.

(2) Fujishima, A.; Honda, K. Nature 1972, 238, 37.

(3) Maeda, K.; Domen, K. J. Phys. Chem. C 2007, 111, 7851.

(4) Kamat, P. V. J. Phys. Chem. C 2007, 111, 2834.

(5) Osterloh, F. E. Chem. Mater. 2008, 20, 35.

(6) Maeda, K.; Takata, T.; Hara, M.; Saito, N.; Inoue, Y.; Kobayashi, H.; Domen, K. J. Am. Chem. Soc. 2005, 127 (23), 8286-8287.

(7) Maeda, K.; Teramura, K.; Saito, N.; Inoue, Y.; Kobayashi, H.; Domen, K. Pure Appl. Chem. 2006, 78 (12), 2267-2276. 3659 .

(9) Yesodharan, E.; Yesodharan, S.; Graetzel, M. Sol. Energy Mater. 1984, $10,287$.

(10) Kiwi, J.; Grätzel, M. J. Phys. Chem. 1984, 88, 1302.

(11) Duonghong, D.; Grätzel, M. J. Chem. Soc., Chem. Commun. 1984, 1597.

(12) Ebina, Y.; Sakai, N.; Sasaki, T. J. Phys. Chem. B 2005, 109, 17212.

(13) Kudo, A.; Kato, H.; Nakagawa, S. J. Phys. Chem. B 2000, 104, 571.

(14) Tabata, S.; Ohnishi, H.; Yagasaki, E.; Ippommatsu, M.; Domen, K. Catal. Lett. 1994, 28, 417.

(15) Sayama, K.; Arakawa, H. J. Chem. Soc., Chem. Commun. 1992, 150.

(16) Sayama, K.; Arakawa, H. J. Photochem. Photobiol., A 1994, 77, 243.

(17) Arakawa, H. Water Photolysis by $\mathrm{TiO}_{2}$ Particles-Significant Effect of $\mathrm{Na}_{2} \mathrm{CO}_{3}$ Addition on Water Splitting. In Photocatalysis Science and Technology; Kaneko, M., Okura, I., Eds.; Springer: New York, 2002; p 235.

(18) Kiwi, J.; Graetzel, M. J. Mol. Catal. 1987, 39, 63.

(19) Kalyanasundaram, K.; Grätzel, M.; Pelizzetti, E. Coord. Chem. Rev. 1986, 69, 57

(20) Gu, B.; Kiwi, J.; Grätzel, M. New J. Chem. 1985, 9, 539.

(21) Goto, H.; Hanada, Y.; Ohno, T.; Matsumura, M. J. Catal. 2004, $225,223$.

(22) Augustynski, J. Electrochim. Acta 1993, 38, 43.

(23) Ulmann, M.; Detacconi, N. R.; Augustynski, J. J. Phys. Chem. 1986, 90,6523 .

(24) Domen, K.; Yoshimura, J.; Sekine, T.; Tanaka, A.; Onishi, T. Catal. Lett. 1990, 4, 339.

(25) Ebina, Y.; Tanaka, A.; Kondo, J. N.; Domen, K. Chem. Mater. 1996, 8, 2534.

(26) Takata, T.; Tanaka, A.; Hara, M.; Kondo, J. N.; Domen, K. Catal. Today 1998, 44, 17.

(27) Ebina, Y.; Sasaki, T.; Harada, M.; Watanabe, M. Chem. Mater. 2002, 14, 4390 .

(28) Yamashita, Y.; Hyuga, K.; Petrykin, V.; Kakihana, M.; Yoshimura, M.; Domen, K.; Kudo, A. J. Ceram. Soc. Jpn. 2007, 115, 511.

(29) Compton, O. C.; Mullet, C. H.; Chiang, S.; Osterloh, F. E. J. Phys. Chem. C 2008, 112, 6202.

(30) Carroll, E. C.; Compton, O. C.; Madsen, D.; Larsen, D. S.; Osterloh, F. E. J. Phys. Chem. C 2008, 112, 2394.

(31) Compton, O. C.; Carroll, E. C.; Kim, J. Y.; Larsen, D. S.; Osterloh, F. E. J. Phys. Chem. C 2007, 111, 14589.

(32) Proper, R.; Rosenthal, R. W. Chem. Anal. 1956, 45, 79. 
(33) Jacobsen, A. J.; Johnson, J. W.; Lewandowski, J. T. Inorg. Chem. 1985, 24, 3727 .

(34) Fang, M. M.; Kim, C. H.; Saupe, G. B.; Kim, H. N.; Waraksa, C. C.; Miwa, T.; Fujishima, A.; Mallouk, T. E. Chem. Mater. 1999, 11, 1526.

(35) Kuhn, H. J.; Braslavsky, S. E.; Schmidt, R. Pure Appl. Chem. 2004, 76,2105

(36) Pilipenko, A. T.; Shevchenko, L. L.; Patselyuk, V. A. J. Appl. Spectrosc. 1970, 14, 473.

(37) Andrade, J. S. d.; Pinheiro, A. G.; Vasconcelos, I. F.; Sasaki, J. M.; Paiva, J. A. C. d.; Valente, M. A.; Sombra, A. S. B. J. Phys.: Condens. Matter 1999, 11, 4451.

(38) Nakamoto, K. Infrared and Raman Spectra of Inorganic and Coordination Compounds, 5th ed.; Wiley-Interscience: New York, 1997.

(39) Bayot, D.; Tinant, B.; Devillers, M. Catal. Today 2003, 78, 439.
(40) Bayot, D.; Devillers, M.; Peeters, D. Eur. J. Inorg. Chem. 2005 , 20,4118

(41) Black, J. R.; Nyman, M.; Casey, W. H. J. Am. Chem. Soc. 2006, $128,14712$.

(42) Stomberg, R. Acta Chem. Scand. A 1983, 37, 523.

(43) Mathern, G.; Weiss, R. Acta Crystallogr., Sect. B 1971, B 27, 1582.

(44) Bayot, D.; Tinant, B.; Devillers, M. Inorg. Chem. 2005, 44, 1554.

(45) Fox, M. A.; Dulay, M. T. Chem. Rev. 1993, 93, 341.

(46) Carp, O.; Huisman, C. L.; Reller, A. Prog. Solid State Chem. 2004, 32,33 .

(47) Halmann, M. M. Photodegradation of Water Pollutants; CRC Press: Boca Raton, FL, 1996.

(48) Kamat, P. V. J. Phys. Chem. B 2002, 106, 7729.

(49) Vinodgopal, K.; Hotchandani, S.; Kamat, P. V. J. Phys. Chem. 1993, 97, 9040.

JP807839B 